\title{
Rapidly progressive pulmonary fibrosis in a patient treated with danazol for idiopathic thrombocytopenic purpura
}

\author{
Smita Pakhale MD ${ }^{1}$, Yuri Moltyaner MD FRCPC ${ }^{1}$, Dean Chamberlain MD FRCP ${ }^{2}$, Neil Lazar MD FRCPC ${ }^{1}$
}

S Pakhale, Y Moltyaner, D Chamberlain, N Lazar. Rapidly progressive pulmonary fibrosis in a patient treated with danazol for idiopathic thrombocytopenic purpura. Can Respir J 2004;11(1):55-57.

\begin{abstract}
The case of a patient that developed pulmonary fibrosis two months after initiation of danazol for treatment of idiopathic thrombocytopenic purpura is described. Bilateral pneumothoraxes and pneumomediastinum complicated the rapidly fatal pulmonary fibrosis. An association between danazol therapy and the development of pulmonary fibrosis is suspected. There is only one other case report with this connection in the literature.
\end{abstract}

Key Words: Danazol; Idiopathic thrombocytopenic purpura; Pulmonary fibrosis

diopathic thrombocytopenic purpura (ITP) is an autoim1 mune disease resulting from antibodies directed against antigens on platelet glycoproteins, leading to accelerated platelet clearance by phagocytic cells. The mainstay of treatment for patients with ITP is corticosteroids, although intravenous immunoglobulin and splenectomy is used in certain settings. Refractory ITP has been treated with immunosuppressive drugs, anti-Rhesus D and danazol. Danazol, an attenuated androgen, has been effective in increasing platelet counts in doses ranging from $50 \mathrm{mg} /$ day to $800 \mathrm{mg} /$ day $(1,2)$. The mechanism of action is postulated to be danazol-induced reduction of Fc receptors on phagocytic cells $(1,2)$.

In the literature, the short and long term safety of danazol has been described, and there are two reports of pulmonary complications (3-7). We present the case of a woman with ITP who developed pulmonary fibrosis and pneumothoraces while on danazol for refractory ITP.

\section{CASE PRESENTATION}

In June 1998, a 78-year-old woman was found to have a low platelet count on routine blood work. Other than mild osteoarthritis, she was previously well. She was admitted to a local hospital for further investigations. Though she denied any bleeding tendencies, petechiae were present on her trunk. Bone marrow aspiration and biopsy revealed normal megakaryocytes and decreased iron stores. The workup for secondary causes of thrombocytopenia was negative, and she was diagnosed with
Fibrose pulmonaire à évolution rapide chez un patient traité au danazol pour un purpura thrombocytopénique idiopathique

\begin{abstract}
Voici un cas de fibrose pulmonaire qui est apparue deux mois après l'amorce d'un traitement au danazol pour un purpura thrombocytopénique idiopathique. Des pneumothorax bilatéraux et un pneumomédiastin sont venus compliquer la fibrose pulmonaire, qui a évolué rapidement vers la mort. On soupçonne l'existence d'un lien entre le traitement au danazol et l'apparition de la fibrose pulmonaire. Toutefois, la documentation ne fait état que d'un seul autre cas de même nature.
\end{abstract}

ITP. Prednisone was started at $100 \mathrm{mg} /$ day, but the platelet count did not rise above $10 \times 10^{9} / \mathrm{L}$. She was treated with intravenous immunoglobulin, and her platelet count rose to $60 \times 10^{9} / \mathrm{L}$. She was discharged home on prednisone $100 \mathrm{mg} / \mathrm{day}$.

On follow-up three weeks after discharge, the platelet count had decreased to $12 \times 10^{9} / \mathrm{L}$. Treatment with danazol $200 \mathrm{mg}$ three times daily by mouth was added to the prednisone. After six weeks of treatment with danazol, she presented to an emergency room with shortness of breath and pleuritic chest pain. There was no history of exposure to any organic or inorganic dust. On examination, she was hypoxic with an arterial oxygen saturation of $87 \%$ in room air. Her respiratory rate was 36 breaths/min, and she was in moderate respiratory distress. There was no clubbing or cyanosis. Auscultation of the chest revealed reduced breath sounds on the right side and coarse crackles bilaterally. The rest of the examination was normal. A chest $\mathrm{x}$-ray showed bilateral pneumothoraxes (right side greater than left) and bilateral diffuse interstitial infiltrates. The chest $\mathrm{x}$-ray taken at the time of presentation with ITP had been normal. Bilateral intercostal drainage tubes were inserted. A high resolution computed tomography (HRCT) scan showed interstitial lung disease involving predominantly the lower lung zones (Figure 1). Her immunological workup, including rheumatoid factor, antinuclear antibodies and antineutrophilic cytoplasmic antibodies, was negative. Serology for hepatitis $\mathrm{B}$ and $\mathrm{C}$ was also negative. Results of $\mathrm{C} 3, \mathrm{C} 4$ and serum immunoelectrophoresis were normal. On bronchoscopy,

Departments of ${ }^{1}$ Respirology and ${ }^{2}$ Pathology, Toronto General Hospital, Toronto, Ontario

Correspondence: Dr Smita Pakhale, 2 Norcross Crescent, Winnipeg, Manitoba R3X 1H8. Telephone 204-257-2827, fax 204-787-1333

e-mailsmita.pakhale@utoronto.ca 


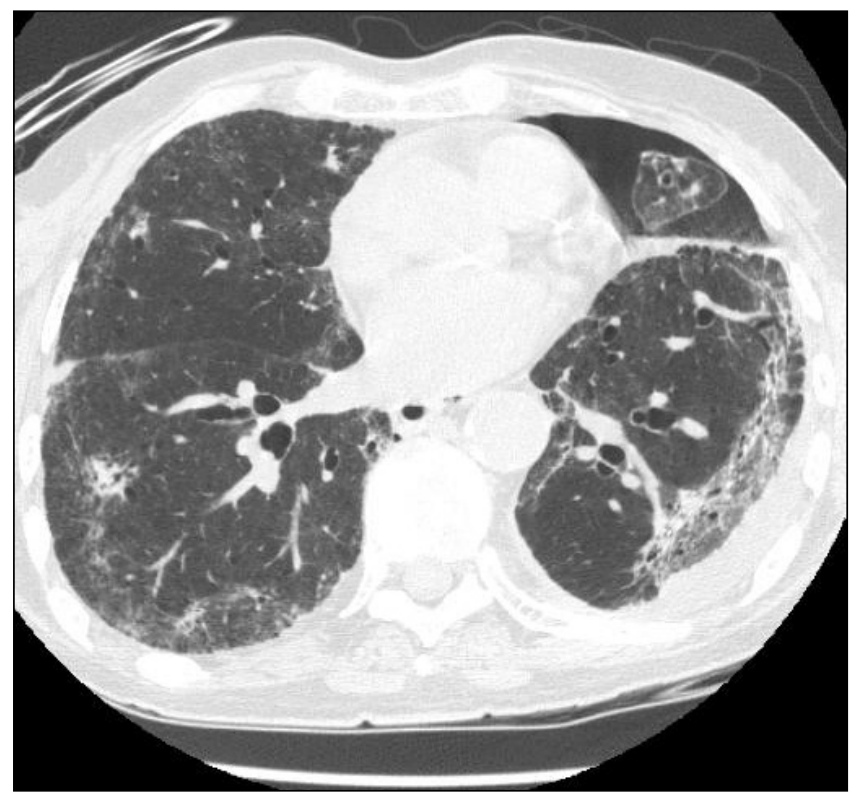

Figure 1) High resolution computed tomography scan of the lungs showing bilateral peripheral thickening of the interstitium with patchy air space disease, worse on the left side than on the right. A small pneumothorax is seen on the left side anteriorly

the visualized airways appeared normal, and bronchoalveolar lavage was negative for bacteria, fungus, mycobacteria and malignancy. Differential cell count could not be obtained because the sample was inadequate. Her platelet count was normal throughout her hospital stay. She was transferred to a tertiary care centre for an open-lung biopsy. A biopsy of the left lower lobe and lingula revealed an acute interstitial pneumonia (6) of proliferative to fibrotic nature. Predominantly, there were mixed lymphocyte/plasma cell infiltrates, interstitial and air space fibrosis, and alveolar lining cell regenerative atypia. Fibrosis was more severe in the lingula and appeared to be rapidly progressive, resulting in distortion of air spaces and cystic remodelling of lung parenchyma (Figure 2). There were no granulomatous or eosinophilic component and no findings specific for etiology, including examination for microorganisms and viral cytopathic effects. Cultures of biopsy tissue for bacteria, mycobacteria, fungi and Legionella species were negative. After the lung biopsy, she was discharged home on treatment with prednisone $100 \mathrm{mg} /$ day, danazol $200 \mathrm{mg}$ three times daily and oxygen.

Two weeks after discharge, she was readmitted with worsening shortness of breath and intermittent chest pain. At this stage, her oxygen requirement increased and she was desaturating to $70 \%$ on $10 \mathrm{~L} / \mathrm{min}$ of oxygen. A repeat HRCT revealed pulmonary fibrosis as well as a pneumomediastinum, left pneumothorax and bilateral pleural effusions. She was treated with a left intercostal drainage tube. The pleural fluid revealed a nonmalignant transudative effusion. Abnormalities in her blood work were significant for liver dysfunction (aspartate aminotransferase $331 \mathrm{U} / \mathrm{L}$, alanine aminotransferase $337 \mathrm{U} / \mathrm{L}$, alkaline phosphatase $575 \mathrm{U} / \mathrm{L}$, bilirubin $24 \mu \mathrm{mol} / \mathrm{L}$, albumin $27 \mathrm{~g} / \mathrm{L}$ and international normalized ratio 1.05). An ultrasound of the liver and biliary system did not reveal any

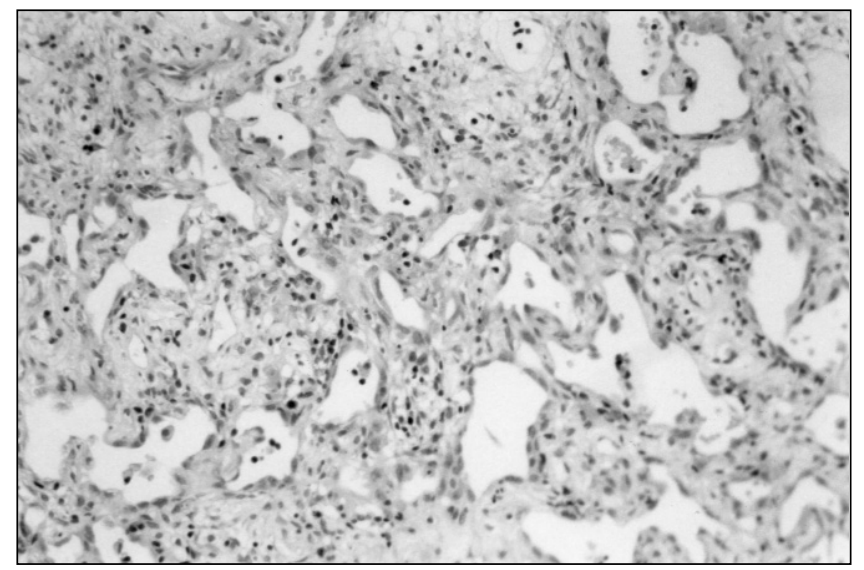

Figure 2) Lung biopsy showing a remodelling of air spaces due to rapidly progressive interstitial fibrosis and alveolar collapse. The air spaces are distorted and lined by regenerating epithelial cells. (Hematoxylin and eosin stain, original magnification $\times 160$ )

abnormality. Tests for serum antimitochondrial antibody was negative. Treatment with danazol was discontinued, and cyclophosphamide $50 \mathrm{mg} /$ day was added to the prednisone $100 \mathrm{mg} /$ day. The prednisone was tapered to $50 \mathrm{mg} /$ day over two weeks. Her serum transaminase level decreased to $112 \mathrm{U} / \mathrm{L}$, but the alkaline phosphatase level continued to rise to $2200 \mathrm{U} / \mathrm{L}$. She spent the next two months with the geriatric rehabilitation service, but her respiratory status did not improve. She was discharged home with home care and died of respiratory failure one month later.

\section{DISCUSSION}

The present case suggests an association between therapy with danazol and rapidly progressive pulmonary fibrosis. The patient developed pulmonary symptoms, as well as chest $\mathrm{x}$-ray and HRCT abnormalities after the introduction of danazol. There did not appear to be any other confounding factors. Elevation of liver enzymes also occurred while on danazol therapy. This is a commonly reported side effect $(2,5)$. Given the extensive fibrosis and a rapidly deteriorating clinical course, we were unable to assess the effects of danazol withdrawal on the liver and lung.

There is one case reported in the literature of possible danazol-associated fatal pulmonary fibrosis (7). A 72-yearold man with chronic lymphocytic leukemia was treated with danazol to taper steroid therapy. He developed rapidly progressive pulmonary fibrosis and died within 15 days of diagnosis. The only other danazol-associated pulmonary complication published in the literature is hypersensitivity pneumonitis in one patient (8). There is no mention of any possible mechanism of action causing lung injury in the literature.

\section{CONCLUSIONS}

The present case suggests an association between danazol use and the development of pulmonary fibrosis. Although this cause-and-effect relationship was not proven, it is suggested that patients treated with danazol should be followed up carefully for pulmonary symptoms. 


\section{REFERENCES}

1. Parker Levine S. Thrombocytopenia Caused by Immunologic Platelet Destruction. In: Lee GR, ed. Wintrobe's Clinical Hematology, vol 2. Baltimore: Williams \& Wilkins, 1998;1583-611.

2. Blanchette V, Freedman J, Garvey B. Management of chronic immune thrombocytopenic purpura in children and adults.

Semin Hematol 1998;35(Suppl 1):36-51.

3. Jick SS, Myers MW. A study of danazol's safety. Pharmacotherapy 1995;15:740-1.

4. Chuong CJ, Monsalve JA. Long-term danazol administration. Int J Gynaecol Obstet 1996;53:61-2.

5. Zurlo JJ, Frank MM. The long-term safety of danazol in women with hereditary angioedema. Fertil Steril 1990;54:64-72.
6. American Thoracic Society; European Respiratory Society. American Thoracic Society/European Respiratory Society International Multidisciplinary Consensus Classification of the Idiopathic Interstitial Pneumonias. Am J Respir Crit Care Med 2002;165:277-304.

7. Grange MJ, Dombret MC, Fantin B, Gougerot-Pocidalo MA. Fatal acute pulmonary fibrosis in a patient treated by danazol for thrombocytopenia. Am J Hematol 1996;53:149.

8. L'Huillier JP, Quinquivel ML, Desrues B, et al. Le danazol: Une nouvelle etiologie de pneumopathie d'hypersensibilité? Rev Mal Respire 1990;7:106. 


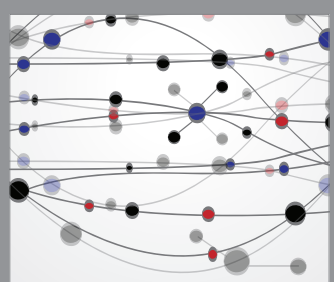

The Scientific World Journal
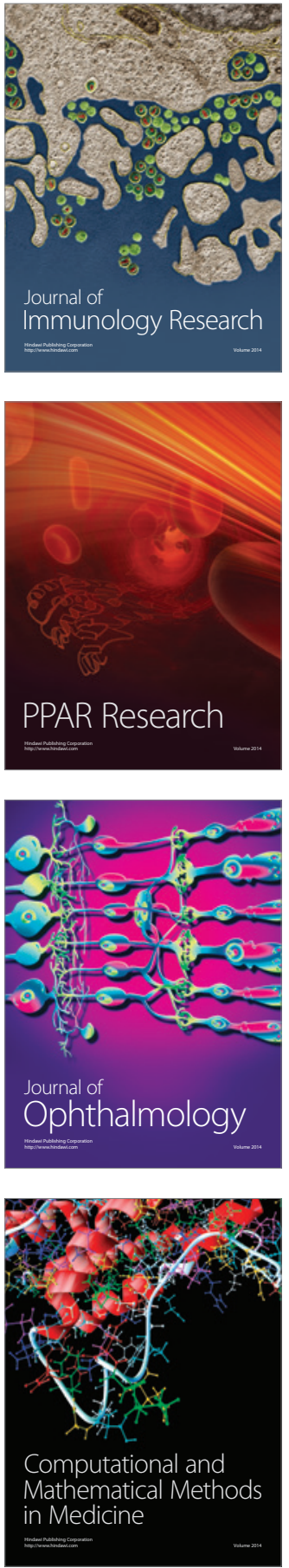

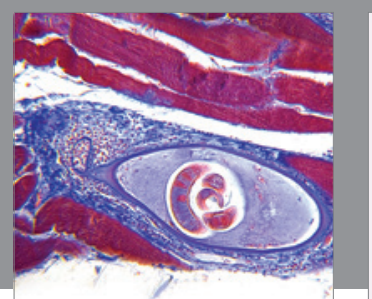

Gastroenterology Research and Practice

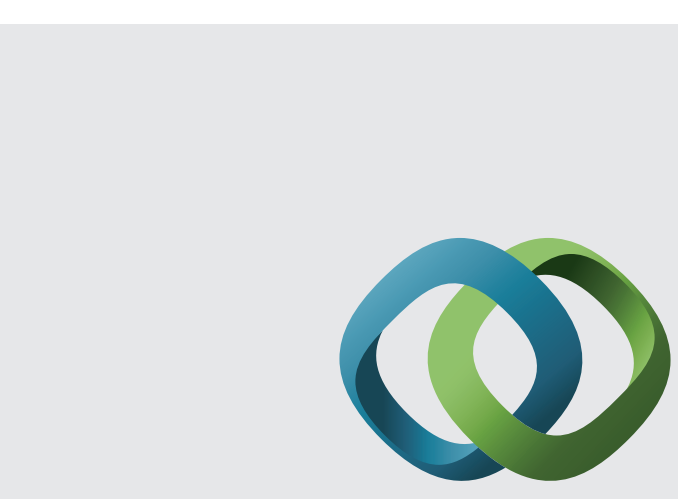

\section{Hindawi}

Submit your manuscripts at

http://www.hindawi.com
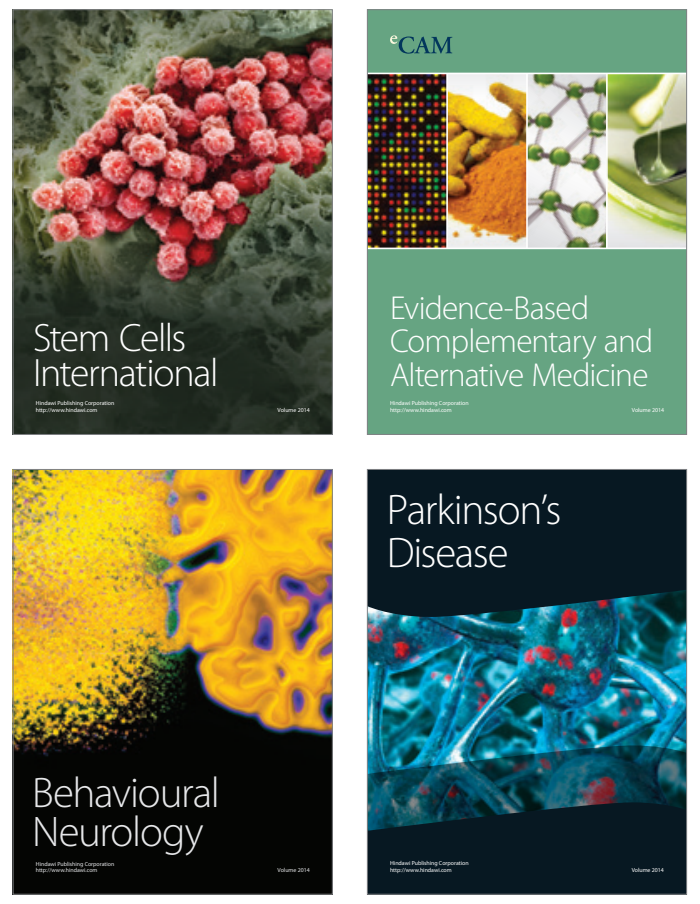
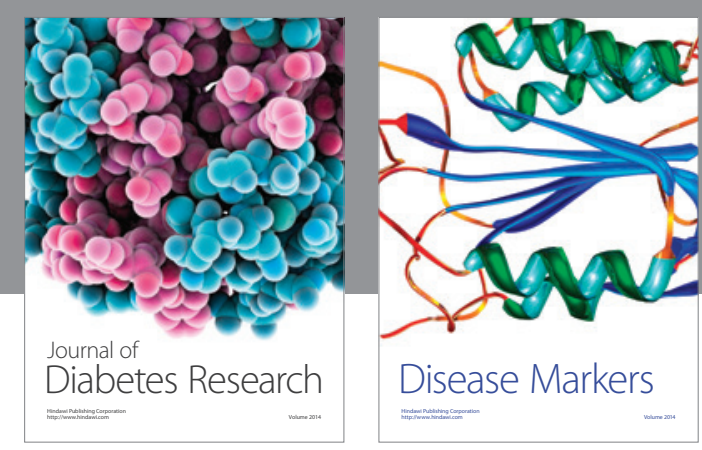

Disease Markers
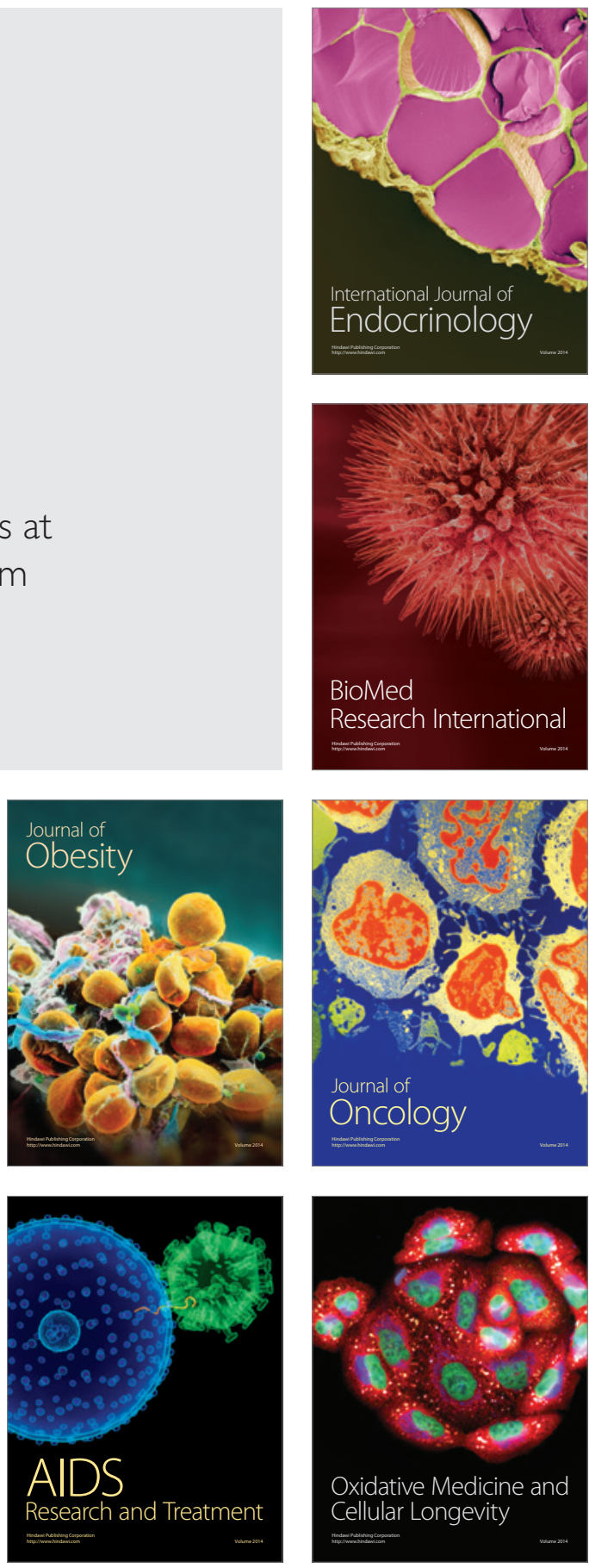